\title{
Tradition, tradition
}

\author{
"Without our traditions, our lives would be as shaky as ... as . . . as a fiddler on the roof!" \\ -Tevye, Fiddler on the Roof
}

\begin{abstract}
Starting with this issue, the Editorial duties for the JCI move to Duke University and the University of North Carolina at Chapel Hill. As we begin our five-year tenure at the helm of this prestigious journal, the tradition of excellence that these two schools typically display on the basketball court now enters the editorial boardroom.
\end{abstract}

On May 10, 1909, Samuel Meltzer gave a stirring presidential address to the first meeting of the American Society for Clinical Investigation (1). His words were a clarion call to the rebellious Young Turks who joined together to form this new Society because the other societies at the time were out of touch with their needs. One of the goals of this Society was to have a forum where physician-scientists could report the results of their scientific discoveries. And, to this end, in 1924 the Journal of Clinical Investigation was born. Now, 88 years later, the JCI Editorial Board begins a new five-year term at Duke University and the University of North Carolina at Chapel Hill. As I assume the responsibility as Editor-in-Chief, I am humbled by the rich tradition of the JCI and its awesome responsibility as articulated by Alfred E. Cohn in his 1924 editorial (2): "Its business [that of clinical investigation] involves a legitimate interest in learning as well as a means for furthering the methods which lead to the cure of disease." Our new Editorial Board will uphold this tradition of excellence that has defined the JCI over the last century and will strive to publish the best in biomedical science. Indeed, it is my goal that JCI publish disease-based investigation that makes both a new discovery that significantly impacts the thinking in the field and has the potential to lead to a new therapeutic advance. After reading a JCI article, I want our readers to sit back and say "Wow, what an amazing discovery - what a beautiful story."

The legacy of excellence that we inherit at the Journal happened not by accident, but rather because of the hard work and dedication of past editorial boards. For the past five years, the Editorial Board led by Larry Turka and his team at the University of Pennsylvania has shaped the JCI into a journal that we can be truly proud of. From their commitment to publishing the best in biomedicine to their uncompromising ethical principles, the JCI shines today in no small measure due to UPenn's outstanding stewardship of the Journal. I am immensely grateful to the UPenn Editorial Board for handing over the reins with the JCI on such solid footing.

The new Editorial Board is made up of distinguished faculty from Duke University, the University of North Carolina at Chapel Hill, the Duke-NUS Graduate Medical School in Singapore, and the Sanford-Burnham Medical Research Institute. Unlike a number of other toptier journals, a distinguishing feature of the JCI is that knowledgeable scientists in the field perform the initial evaluation of submitted manuscripts for scientific rigor and we meet in person every week to discuss these manuscripts. I have brought together an Editorial Board with broad biomedical expertise that will continue the JCI's tradition of scientific excellence and is committed to providing fair and rapid scientific review. As Editor-in-Chief, I plan to set a culture for the Board that provides rigorous scientific review, but avoids asking authors to perform endless additional experiments that needlessly prolong the review period without adding to the scientific merit of the study. I am also very proud of the Journal's policy of free access to all research articles. This is particularly important given the recent misguided legislation introduced in the House of Representatives to prevent the NIH from providing free access to federally funded research papers within a year of publication (3).

So, you might be asking, what do I think makes a JCI paper? Simply stated: "scientific excellence and clinical significance." I believe that the JCI should continue to publish biomedical research that makes a new discovery, significantly impacts the thinking in the field, and points toward clinical translation. A JCI paper should be rigorous and comprehensive so that it moves the field forward, creates new knowledge, reveals new mechanisms, and advances our understanding of the biology of disease and/or treatment. Purely methodological or in vitro studies will not likely constitute a JCI paper. I also believe that the use of multiple model systems will enhance quality, and I would like to see more papers that identify a gene or molecule in an invertebrate model system, use cellular systems to understand a mechanism, and report gain- and loss-of-function experiments in a mammalian system to test a mechanism that leads to translation in humans. While a bar this high is likely not attainable in all instances, we hope that investigators will use the creative combination of as many of these approaches as possible in their submitted work. I also encourage the submission of investigator-initiated studies in humans, combined with cellular and molecular mechanistic studies.

While I am committed to maintaining the tradition of the Journal, I also plan to experiment with new features to keep the $J C I$ at the cutting edge of scientific publishing. One area from which to start is the frontmatter. The frontmatter of the JCI is an expression of its personality. While I plan to introduce a number of initiatives to enhance the Journal's readership and visibility, I would like to highlight a few that I think will be of great interest. In a new video series entitled "Conversations with Giants: The Joy of Discovery and Thrill of the Chase," we will interview scientific giants who have transformed the science and practice of medicine to hear about their lives and excitement for scientific discovery. We already have several "giants" who have agreed to take part in this series, and we look forward to posting these video interviews on the JCI website over the next few months. I am delighted that our inaugural conversation is with Harold Varmus, and we will post his interview along with an abbreviated transcript in our April 2012 issue. Also starting in the April issue, we will launch a new series entitled "The Attending Physician," which will be written by a leading clinician who will provide an opinion on therapy of a common clinical problem in connection to a concurrent JCI article that makes a transformational dis- 
covery by providing insight into its mechanism of disease. In a "Hindsight" series highlighting our rich heritage of scientific excellence, we will probe the JCI archives for landmark publications that have changed a scientific field. Our first Hindsight article is by Ralph Nachman on the first successful culture of endothelium. Accompanying articles of special interest will be a short (10-minute) online webinar containing 8-10 slides narrated by the author describing their exciting new discovery. Last, we will post online a monthly essay series from Alex Fanaroff, a physician-scientist in the midst of clinical training, to learn about his experiences during the rigors of residency. Physician-scientists in training are encouraged to comment on our new JCI blog. I am excited about these new initiatives and look forward to hearing from you about them and welcome your suggestions for future content.

The professional editorial team is critical to the success of the JCI and will continue to play a significant role in both administering the daily flow of work for the review process and also being primarily responsible for the frontmatter. I am delighted that Executive Editor Ushma Neill has agreed to stay on with us, for she has significantly added to the excellence of the Journal. I am equally delighted that Kathryn Claiborn will continue with the JCI and take on additional responsibilities as the Science Editor. I am also fortunate to have John Hawley remain as Executive Director of the ASCI/JCI, along with his extremely talented production team located at the ASCI headquarters in Ann Arbor, Michigan. In the context of deadlines, last-minute edits, and the fast pace of publishing, having such a highly qualified team is truly indispensable for the JCI.

For the past 88 years, the JCI has been a precious resource and outlet for the scientific community, filled with amazing discoveries and paradigm-shifting findings. I want to make sure that the next five years serve the journal well and am depending on the Editorial Board as well as our authors and reviewers to help us achieve this task. To quote Tevye: "A fiddler on the roof. Sounds crazy, no? ... It isn't easy. You may ask 'Why do we stay up there if it's so dangerous?' Well, we stay because Anatevka is our home. And how do we keep our balance? That I can tell you in one word: tradition!”

I hope to make the JCI your home as we continue the tradition of excellence that the Journal of Clinical Investigation has brought to us for nearly a century.

\section{Howard A. Rockman, Editor in Chief}

1. Howell JD. A history of the American Society for Clinical Investigation. J Clin Invest. 2009; 119(4):682-697.

2. Cohn AE. Purposes in medical research: an introduction to the Journal of Clinical Investigation. J Clin Invest. 1924;1(1):1-11.

3. Eisen MB. Research bought, then paid for. New York Times. January 11, 2012:A27. 